\title{
THE MYZORHYNCHUS GROUP OF ANOPHELINE MOSQUITOS IN MALAYA.
}

\author{
By C. Strickland, M.A., B.C., Cantab., \\ Travelling Medical Entomologist, Federated Malay States.
}

The object of the present paper is to make some remarks about certain of the species and genera mentioned in Leicester's 'Monograph of the Culicidae of Malaya' (1908), together with certain related species described by other authors. I have paid special attention to Leicester's work because it remains the standard book of reference on the mosquitos of Malaya.

The species that will be dealt with are the following:-asiatica, sinensis, annularis, minutus, vanus, barbirostris, umbrosus, paeditaeniatus, separatus and albotaeniatus, which have all been mentioned by one author or another as coming from Malaya. The genera which I propose to discuss are Myzorhynchus, Lophoscelomyia, and Patagiamyia.

\section{The Validity of the Species.*}

The validity of asiatica, barbirostris, umbrosus, and sinensis is not disputed; but concerning the others there has been some doubt and a review of the subject seems desirable.

I. Paeditaeniatus, Leicester (1908). Concerning this species it must be remarked that its sponsor, after weighing all the evidence, dismissed the doubt that it was not a distinct species from sinensis: he said, "The larvae differ constantly from those of $M$. sinensis. In the larva of $M$. sinensis each frontal hair consists of a short thick stem supporting numerous stiff bristle-like hairs, in M. peditaeniatus it is formed by a long thin stem which splits into a few, five or six, fine hairs"; and of the adult fly he said, "The wing scaling also differs from that of $M$. sinensis, as it is much darker and the contrast of the two colours is more pronounced, and the lateral scales are broader. The posterior cross-vein is much nearer the median in $M$. sinensis than in this mosquito"; and again, "In sinensis the yellow scaling of the wing predominates and the brown scales are more or less collected into small spots, while it is exactly the reverse in peditaeniatus."

Now these are definite enough arguments, yet James and Stanton (1911) do not answer them, but on the ground that the leg-banding of sinensis (sensu Leicesteri) is very variable and that therefore the broad leg-bands of paeditaeniatus might be an extreme form of the leg-bands of sinensis, they reject paeditaeniatus as a distinct Malay species. If only the fly itself had been concerned Leicester himself would have probably called it sinensis, for he said, "The real reason for separating them is the differences in the larvae." I agree; for although the distinctive wing-marking of paeditaeniatus and sinensis mentioned above, which is given by Leicester, is certainly often seen, yet every intermediate type

* The validity of the species is here considered on morphological grounds only. 
can be found. In one undoubted paeditaeniatus in my possession the wing-marking was even the exact reverse of Leicester's description, the wing-scaling being largely yellow with brown spots; and I have often seen sinensis with the scaling of the wings very largely brown. The position of the cross-veins is quite as variable also. The broad golden leg-bands of paeditaeniatus are again, as James and Stanton also say, connected by every type of intermediate form with those of sinensis. The costal spots are the same in both species, and the apical fringe spot varies from a size similar to what it is in umbrosus to a broad band visible to the naked eye, and this is not correlated at all with the amount of leg-banding. We must therefore conclude that on morphological grounds it is impossible to say that pueditaeniatus, if the imago only is considered, is a distinct species.

We are then confronted by the difficulty that although the imagines of the two species run into one another, yet only two types of larvae are known, according to Leicester, one of which produces his paeditaeniatus fly and one his sinensis.

Now if these larvae are really distinct and no intermediate forms exist between them, it is enough reason to establish the validity of two species, even though the imagines cannot be distinguished. But I surmise the as yet undiscovered existence of larval intermediate forms which perhaps produce the fly intermediate forms which Leicester has not described.

Leicester's observation at any rate shows an interesting correlation between larval and imaginal structure of extreme forms within a species. If he had not stated that this correlation of structure was constant, we might have explained his observation as illustrating the larval variability which Stanton (1911) has found, but weighing all the evidence, $I$ think that we are justified in assuming that pueditaeniatus is the same species as sinensis.

II. Annularis, Wulp (1884). It is perhaps unnecessary to mention this species, as it has been generally regarded as synonymous with vanus.

III. Vanus, Walk. (1860). This species appears in Theobald (1903 and subsequently), but no writer on Malayan Anophelines has mentioned it. Forms corresponding to Theobald's description certainly occur, but they are not distinct from sinensis, being connected by every possible intermediate form, and the species must therefore be sunk.

IV. Minutus, Theo. (1903). The same remarks apply to this species as to vanus, and it cannot therefore stand as a distinct species.

V. Albotaeniatus, Theo. (1903). Theobald, Leicester, and Alcock, all give this as a distinct species, but James and Stanton, after saying they have not seen it, do not give it a place in their list of Malayan Anophelines. However, it is perfectly distinct, and $I$ have never seen intermediate forms between it and umbrosus, its nearest relative. Besides myself, Dr. Watson of Klang, F.M.S., has seen it on several occasions.

VI. Separatus, Leic. (1908). Leicester gave definite reasons why he thought this a distinct species from sinensis. He said "The points of distinction seem constant, the brown mesonotum, white apical palpal joint, and predominant yellow scaling distinguish it." James and Stanton later endorsed this view, but Leicester's reasons, as a matter of fact, are not very satisfactory, for the points of distinction from sinensis given by him seem to be rather points of resemblance to his own description of sinensis; although in another place he says, "This 
mosquito has no ventral scale-tuft, which is one of the marked characteristics of members of this genus, including sinensis." Certainly sinensis (sensu restricto) has also a brown mesonotum, white apical palpal segment, and predominant yellow wing-scaling, so the only point of difference apparently remaining is the ventral scale-tuft. Now, concerning this, it is true that forms without any ventral scale-tuft are very common, but forms with every intermediate type of structure between them and sinensis exist, and I therefore think that scparatus is not a distinct species from sinensis. If it is, I do not know where the line can be drawn in practice. Leicester himself said that it might be a variety of sinensis ; but $I$ do not think that a collection of forms connected with a species by a whole series of intermediate types should be even called a variety of the species, which implies a distinct group. The scaling of the last segment of the abdomen is not important specifically. I have seen undoubted sinensis (sensu restricto) with, or without, scales on the dorsum also of the last segment, and also specimens bred out from the same pond and killed immediately, one with a heavy ventral tuft, one with only a few scales in the tuft, and one with no tuft at all. There could be no question of the tuft having been rubbed off, for the specimens were in a perfect condition otherwise, ${ }^{*}$ and these forms with only a few scales in the ventral tuft are common enough.

In fact, it only needs a month or two's work with so-called sinensis, annularis, vanus, paeditaeniatus, separatus, and minutus, to prove that it is impossible to separate them up into morphological groups. I therefore recognise only the following as valid speciest :-barbirostris, sinensis, umbrosus, asiatica, and albotaeniatus.

\section{The Generic Grouping.}

With regard to the generic grouping of the five species which we have considered valid, it must be remarked that Leicester (1908) named asiatica a Lophoscelomyia, and referred the other four species, sinensis, barbirostris, umbrosus, and allotaeniatus, to Myzorhynchus. However James and Stanton (1911) placed umbrosus in the genus Patagiamyia, this genus having been created by James and Liston for species such as umbrosus and albotaeniatus which have patagial tufts, but have no ventral tuft on the eighth abdominal segment. It may certainly be possible that a distinct group exists in India of these mosquitos, but in Malaya these are united to the forms known to James and Liston as Myzorhynchus (which have a ventral abdominal tuft) by a whole series of annectant forms. For example:-

(1) sinensis is represented here by specimens which have or have not the ventral abdominal tuft ;

(2) barbirostris has likewise occasionally forms with or without an abdominal tuft;

* I have had a barbirostris with no ventral tuft on the eighth segment, but with small tufts on the other segments.

$\dagger \mathbf{A}$ new species, which I have not seen, has just been described in the Journal of the London School of Tropical Medicine. 
(3) umbrosus has sometimes its last abdominal segment clad with scales, and it is therefore not improbable that occasionally these take the form of an outstanding tuft;

(4) barbirostris has sometimes a series of ventral tufts, a fact indicating that the presence or not of such scales is not of much importance phylogenetically ;

(5) the females only are ever tufted, the males cannot be grouped into genera morphologically except by reason of their relationship to the females.

In short, species which are placed by James and Stanton (1911) into two genera have forms in Malaya which run into one another, and it is impossible to distinguish two distinct groups of them.

Similarly we have evidence that the genus Lophoscelomyia is the same as Myzorhynchus. Alcock (1911) came to the conclusion that this was so, and referred asiatica to his subgenus Myzorhynchus. Now Lophoscelomyia is distinguished from Myzorhynchus by the presence on the femora of the outstanding tuft of scales in the former which is absent in the latter, as well as scales on the dorsum of the last abdominal segment, supposed to be absent in Myzorhynchus. But-

(1) I have found a barbirostris with tufted femora as in asiatica ;

(2) I have found specimens of umbrosus and barbirostris with the last abdominal segment clad with flat scales, which is one of the main points of the genus Lophoscelomyia;

(3) the wings of all the species placed in Lophoscelomyia or Myzorhynchus are marked in a strikingly similar manner; thus the costa has nearly always two golden spots or rudimentary spots, one at the junction with the subcostal and one at the junction with the first longitudinal vein ; the first of these nearly always involves the first longitudinal, while the second nearly always involves the upper branch of the second longitudinal; the lower branch of the second longitudinal has also nearly always an area of light-coloured scales and the wing-fringe has always a golden spot opposite the junction of the third long vein ; and

(4) Lophoscelomyia has patagial tufts like Myzorhynchus, and its clothing of hairs and scales is essentially similiar.

I conclude therefore with Colonel Alcock that Lophoscelomyia is not distinct from Myzorhynchus, and that the five species sinensis, barbirostris, umbrosus, albotaeniatus, and asiatica form generically one group.

I note that Colonel Alcock on the other hand would not divide up the Anophelines into groups at all, but would call them all Anopheles. But the species here discussed form such a well-defined group that $I$ think myself that it would be 'defeating the humane objects of a natural classification' not to knit together under a separate title obviously related forms such as these, and I therefore suggest that the genus Myzorhynchus do stand.

\section{The Morphology of the Species.}

In the descriptions which follow, the imagines only are concerned, as the morphology of the other stages has not been considered, and the plan adopted 
will be to give, after making a few preliminary remarks, (1) a 'definition' of the species in as simple terms as possible, which will be exclusive (in Malaya) for the species under discussion; (2) the general naked-eye appearance; and finally (3) the complete revised description.

\section{Myzorhynchus sinensis, Wied.}

Remarks. The wing marking has no specific character except the two costal spots and the apical fringe spot; the abdominal ventral tuft is not a specific character.

Definition. Mosquito with banded palps and not more than two costal spots.

Naked-eye appearance. Dark brownish black mosquito without obviously dappled wings; its palps not half as wide as the head.

Description. Head: on the vertex a tuft of long white scales projecting forward, on the occiput a patch of bluish white upright scales, on the nape and cheek dark brown upright scales. Palpi with four narrow bluish white bands. Proboscis all black. Thorax clad with long golden hairs; patagia with a dense cockade of palisade scales. Wings clad with dark chocolate-brown, golden and creamy scales; the costa with brown scales broken by two golden spots, ono where the subcustal vein joins the costal, and one where the first longitudinal meets the apex; the wing-fringe golden at a spot at the apex. Legs dark brown, except for golden banding at the articulations; the extremity of the fifth tarsal segment dark brown. Abdomen dark brown, clad with long golden hairs.

\section{Myzorhynchus barbirostris, van der Wulp.}

Remarks. I have found this species without a white spot in the wing-fringe opposite the lower branch of the fifth long vein, so it can no longer be considered that this character is specific. I have also found specimens without a ventral abdominal tuft on the eighth segment, and it is almost certain that the tuft in these specimens had not been rubbed off, because on each of the other abdominal segments there was a small undamaged tuft of black scales. I thought at first that these represented a new species, but the large black shaggy palps, and the white spot on the wing-fringe, so common in this species, could not be disregarded.

Definition. Mosquito with black palps, more than half the width of the head at their base.

Naked-eye appearance. A black mosquito with very heavy mouthparts. Wings not dappled.

Description. Head: tuft of long scales projecting forward from the vertex, behind this a few dirty white upright scales, and the rest of the head with black upright scales. Palpi all black, clad with scales which are particularly long at the base and can usually be seen discrete. Proboscis black-scaled. Thorax : prothoracic lobes with a cockade of black palisade scales; mesonotum clad with pale hairs, a tuft of long narrow white scales projecting over the neck, and a tuft of black scales on each shoulder over the patagia. Wings clad with black scales, with yellowish scales mostly over the posterior veins; the costa with two golden spots, one where the subcostal vein joins it, the other where the first longitudinal 
joins the latter, involving also the upper branch of the second long vein ; the fringe with a small golden spot at the apex, at the junction of the third vein. Legs very narrowly banded at the articulations; fifth tarsal segments black. Abdomen black, with dark hairs.

\section{Myzorhynchus umbrosus, Theo.}

Remarks. Dr. Watson, of Klang, has found a variety of this species characterised by two costal spots, but the examination of a large number of specimens of the typical form and of the variety has shewn that the two types are united by annectant forms. The asserted absence of all scales on the abdomen is not a specific character, for I have seen specimens with the last abdominal segment covered with black scales on the dorsum.

Definition. Mosquito with black palps less than half the width of the head and with the last tarsal segment of the hind leg black.

Naked-eye appearance. A blue-black mosquito without obviously banded legs, and the mouth-parts not heavy in appearance. Wings not dappled.

Description. Head: a tuft of long white scales projecting forward over the clypeus from the vertex, behind this a triangular patch of bluish white scales, and elsewhere clad with dark brown upright scales. Palpi and proboscis all black. Thorax: prothoracic lobes with a large cockade of clavate scales; mesonotum clad with pale golden hairs, a tuft of fine white scales anteriorly, and below each shoulder a tuft of dark brown curved scales. Wings with a spot on the costa at the junction with the first long vein; wing-fringe with a small yellow spot at the apex, otherwise black. Legs minutely banded at the articulations. Abdomen black, with pale hairs.

\section{Myzorhynchus albotaeniatus, Theo.}

Remarks. Leicester's specimens were described as having the fifth tarsal segment of the hind leg black at the apex; the specimens which I have seen have been entirely white at that place. Another point is that the latter have all had an apical wing-fringe spot, which appears to have been absent in Leicester's examples.

Definition. Mosquito with black palps, and the hind legs very broadly banded with white.

Naked-eye appearance. A bluish black mosquito, without dappled wings and with the hind legs obviously banded with white.

Description. Head with a tuft of golden hairs and hair-like scales projecting forward from the vertex, on the occiput a few white upright scales, and on the rest dark brownish black upright scales. Palps and proboscis black-scaled. Thorax : patagia with a tuft of dark brown scales on their apices; mesonotum clad with golden hairs. Wings with two costal spots, one small one at the junction of the subcostal vein with the costal, and one at the junction of the first long vein at the apex, which also involves the upper branch of the second long vein. Legs : fore and mid legs narrowly banded, hind legs broadly banded with white, the remainder being black; the banding is complete on the last tarsal segment and extends on to the penultimate segment distally for a third of its length, the next three joints being marked by a broad band which extends on to the segments on each side of the joint. Abdomen black, clad with pale hairs. 


\section{Myzorhynchus asiaticus, Theo.}

Definition. Mosquito with the apex of the hind femur clad with a tuft of long outstanding black scales, succeeded by a tuft of long white ones.

Naked-eye appearance. The tuft of scales on the femora of this mosquito can easily be seen with the naked eye.

Description. Head with a tuft of long white scales projecting forward from the vertex over the clypeus, behind this a patch of whitish upright scales, and on the occiput dark brownish black upright scales. Palpi clad with black scales, except for a few pale ones at the junction of the third and fourth segments. Proboscis black with light-coloured labellae. Thorax : prothoracic lobes with a dense tuft of dark curved scales ; mesonotum with a tuft of white curved scales projecting forward from the promontory, otherwise covered with sparse golden hairs. Wings : costa with two spots, the first at the junction of the subcostal vein, the second at the junction of the first longitudinal, which also involves the upper branch of the second longitudinal ; fringe all black, except for a small yellow spot opposite the junction of the third long vein. Legg : middle pair with a patch of white scales on the apex of the femur, hind legs having at the apex of the femur a dense tuft of outstanding black scales succeeded by a tuft of white scales. Abdomen greenish brown, clad with numerous golden hairs.

\section{Summary.}

The following is a summary of the conclusions arrived at in the foregoing paper :-

(1) the species sinensis, barbirostris, umbrosus, albotaeniatus and asiatica have been considered valid ;

(2) the species vanus, annularis, minutus, paeditaeniatus and separatus have been rejected as invalid;

(3) certain new characters of the valid species have been noticed;

(4) the descriptions of the species have been revised;

(5) the genus Patagiamyia has been rejected, as also the genus Lophoscelomyia, both haring been included in the genus Myzorhynchus;

(6) it is suggested that the Myzorhynchus group forms a series sufficiently distinct from other Anophelines to make it advisable to give it a separate generic title.

\section{References.}

Leicester. 'The Culicidae of Malaya.'-Studies from Institute for Medical Research (1908). Kelly Walsh, Singapore.

James and Stanton. Hong Kong Medical Congress Reports (1911).

James and Liston. 'The Anopheline Mosquitoes of India.' Thacker, Spink \& Co., Calcutta.

\section{Postscript.}

Since writing the above I have received a paper by Dr. A. T. Stanton ("The Anopheles Mosquitoes of Malaya, etc.'-Jl. London Sch. Trop. Med. ii, 1913,"p. 1) which bears directly in several points on the subject reviewed. 
With regard to the validity of certain species, Stanton says anent separatus that he has been unable to satisfy himself that it is distinct from sinensis, and he has retained albotceniatus for the present, pending the examination of more material. I hope however that I have given enough reasons above to shew for certain that separatus is not distinct from sinensis and that albotaeniatus is certainly a distinct species. He rejects paeditaeniatus, annularis, vanus, and minutus as I have also done.

Some points in the descriptions of the species are noted, viz., that umbrosus has one or two spots on the costa, and that barbirostris has a series of small white abdominal ventral tufts ; points with which I agree.

He will not discuss any generic grouping of the species, but names them all Anopheles, following Alcock; I think however that the species mentioned form a group quite well defined from other Anophelines and that we are justified in naming it accordingly as a distinct genus. 